\title{
A MÁQUINA DO POEMA \& A MÁQUINA DO MUNDO: PRIMEIRO ESBOÇO PARA UMA POÉTICA
}

\author{
Antonio Donizeti Pires (UNESP/Araraquara)
}

RESUMO: O presente trabalho objetiva refletir os temas, motivos, mitos, personagens e figuras históricas que migram de uma literatura a outra; ou da literatura erudita para o oral; ou desta para aquelas. O estudo privilegia poesia lírica e vale-se das teorias da literatura comparada e da intertextualidade, da metaliguagem e das artes poéticas - de "escola" ou "pessoa" -, não negligenciando asectos como o conceito de gêneros literários e questões sócio-culturais. Para o momento, refletir-se-á acerca da máquina do poema como emblema da máquina do mundo, conforme plasmada pelos poetas Dante Alighieri, Luís de Camões, Drummond, João Cabral e Haroldo de Campos.

A Universal machina do Mundo se divide em duas partes: Celestial \& elemental.

"Pedro Nunes, Tratado da Sphera (século XVI)

E desse nó a forma universal creio ter visto

Dante - "Paraíso", XXXIII. 91-92

Vês aqui a grande máquina do Mundo, Etérea e elemental

Camões, Os Lusíadas, canto X. 80:1-2

E como eu palmilhasse vagamente uma estrada de Minas, pedregosa, [...]

a máquina do mundo se entreabriu para quem de a romper já se esquivava... Drummond, "A máquina do mundo"

46.2. ninguém fala hoje em dia em maquinária 46.3. do mundo concentrando continentes Campos, A máquina do mundo repensada

$\underline{\mathrm{Um}}$

A compreensão do poema como máquina, ou seja, como objeto construído de linguagem, baseado em leis próprias de composição, já está presente em poetas da Idade Média, do Maneirismo, do Barroco e da modernidade (os românticos alemães, Poe, Baudelaire, Mallarmé), mas é no século XX que tal idéia se acirra. No Brasil, além dos exemplos de Haroldo de Campos e Mário Faustino, entre outros, penso que foi João Cabral de Melo Neto quem mais explorou, de maneira original e radical, a noção do poema como máquina, conforme patenteia a seguinte entrevista do poeta aoJornal de Letras e Artes, de Lisboa, em junho de 1966:

Somos gente de muita textura e pouca estrutura... Eis a razão de meu interesse sempre crescente - desde Serial e Quaderna - pela máquina do poema. A imagem forte 
interessa-me cada vez menos. Durante os anos mais próximos irei ainda explorar o ensemble da composição. (NUNES 1976: 266; grifos do autor)

A maneira como o poeta concebe a metalinguagem e a metapoesia - ao lado de seu trabalho com a linguagem, de sua consciência construtiva, da escolha de seus temas, de sua recusa da "imagem forte" e de sua obsessão pelo exato, pelo claro e pelo contundente -, é em larga medida responsável pela configuração de seu poema como máquina. Conforme afirma João Alexandre Barbosa, a metalinguagem cabralina ultrapassa o tópico simples da poesia sobre poesia e instaura um embate tenso entre a realidade e a expressão dessa realidade pela poesia. Trata-se, de acordo com o crítico, de uma metalinguagem fundante, "que recusa o fácil, o que flui, aquilo que foge do controle da máquina do poema" (BARBOSA 2002: 273), ao mesmo tempo evidenciando que as relações entre realidade e poesia "são antes de tensão e de procura de traduções estruturais do que descritivas, quer disfóricas, quer eufóricas ou apologéticas" (BARBOSA 2002: 284). Trata-se, ainda, de uma "metalinguagem [que] não se esgota em si mesma", que opera sempre como "um instrumento pelo qual [o poeta] vai descobrindo ou recriando a forma das coisas" (BARBOSA 2002: 283) e onde se revela "a persistência de uma meditação acerca da criação poética que se dá na própria composição" (BARBOSA 2002: 298). Metalinguagem, em suma, que "ao mesmo tempo que diz da realidade, diz também de uma maneira específica de sua apreensão pelo poema" (BARBOSA 2002: 299).

Encarecido por Barbosa nos ensaios citados, "A lição de João Cabral" e "A poesia crítica de João Cabral" (ambos reunidos em Alguma crítica, 2002), o exemplo cabralino referenda, em minha opinião, a compreensão profunda que se deve ter da prática metalingüística. Esta não pode ser tida apenas como modismo, como algo fortuito e exterior ao poema, mas como uma das bases fundamentais em que se assenta toda poesia realmente crítica e consciente. Enfim, a prática da metalinguagem e da metapoesia - objeto de teorização recente talvez porque levadas às últimas conseqüências apenas com os poetas da modernidade -, ao exacerbar a consciência crítico-construtiva do poeta e tornar-se fator de valoração e valorização da poesia moderna e contemporânea, ressalta, ao mesmo tempo, que a máquina do poema alimenta-se também de poesia: pois a auto-reflexividade, a auto-referencialidade, a consciência construtiva, o pensar sobre a linguagem, o poema, o poeta e a poesia; em suma, o voltar-se sobre as próprias engrenagens, revelando a concepção engenhosa que a norteia, é um dos movimentos preferidos da máquina do poema.

$\underline{\text { Dois }}$

O tópico da máquina do mundo, como tantos outros topoi velhos conhecidos nossos (o carpe diem, o convite amoroso, o retrato feminino, o ubi sunt?, a roda da fortuna, o universo como livro ou o livro como universo, o não sei quê, a vida como sonho, o mundo como teatro, o mundo às avessas ou em desconcerto etc.), foi aproveitado pela poesia de todos os tempos de maneira bastante variada. Presente entre os gregos e os romanos (Pitágoras, teórico da harmonia, fez com que as sete cordas da lira correspondessem às sete esferas celestes; Publius Terentius Varrus, herdeiro da tradição pitagórica, legou-nos o poema geográfico Corografia, onde vislumbra o giro da terra no eixo etéreo e ouve o som das sete esferas celestes), a máquina do mundo passa pela 
Idade Média (veja-se a Divina comédia de Dante Alighieri e sua representação alegórica do mundo, "elemental" e "Celestial" ao mesmo tempo) e atinge grande apreço no Renascimento. Em consonância com o racionalismo mecanicista, o cientificismo e o humanismo da época, a contemplação alegórica do universo atinge então, segundo Fidelino de Figueiredo, "o requinte último da curiosidade geográfica e astronômica dos espíritos elevados, num tema sublime” (SANT’ANNA 1972: 245). Dir-se-ia, em termos simples, que a máquina do mundo contemplada é a representação poética, literária, das esferas armilares e das cartas de navegação que tanto prestígio tiveram - e tanto auxílio prestaram - na época das navegações e dos grandes descobrimentos. Conforme esse diapasão, o tema aparece em Frei Luís de Sousa e no Tratado da Sphera de Pedro Nunes (citados por Sant'Anna) e, em termos literários, no canto X, oitavas 76 - 80, da epopéia Os Lusíadas (1572), de Camões.

Faço aqui duas observações importantes: a primeira diz respeito ao descompasso entre a concepção alegórica camoniana (francamente medieval, geocêntrica e teocêntrica, de raízes ptolomaico-aristotélicas) e a doutrina heliocêntrica, cuja primeira exposição sistemática data de 1543, com o De revolutionibus de Copérnico. Assim, se o poema camoniano é, por excelência, a epopéia da expansão marítima portuguesa (a parte "elemental" da máquina do mundo), não o é, todavia, a epopéia do propalado cientificismo e racionalismo característicos da época, no que concerne às novas teorias da origem e da dinâmica do universo (a parte "Celestial" da máquina do mundo): faltanos, até onde sei, um grande poema épico da Era Moderna onde o tema fosse pertinentemente explorado. Mas ao fim e ao cabo, essa ausência revela algumas características importantes da modernidade nascente (e de todo o processo de modernização que então se inicia): a substituir o mundo uno, fechado e coeso da Idade Média, está a fratura, a dissociação, a fragmentação, a relatividade. Tais características, diga-se de passagem, serão depois bastante exploradas por poetas líricos como Carlos Drummond de Andrade, cujo poema "A máquina do mundo" (em Claro enigma, 1951), ao recusar o maravilhoso representado pelo tema, o considera apenas como mais uma pedra no meio do caminho.

Essas últimas afirmações nos remetem à segunda observação que julgo importante: Camões, na verdade, estende a descrição da máquina do mundo até a estrofe 142 do canto X, praticamente até o epílogo da epopéia: as duas oitavas seguintes (143 e 144) são o fim da narração, pois tratam da volta do Gama e dos marinheiros ao lar depois de terem gozado na Ilha dos Amores tanto a "elemental" saciedade do corpo quanto a "Celestial" sapiência propiciada pela visão da máquina do mundo. As estrofes 145 a 156, como se sabe, marcam o epílogo do poema, sendo a primeira delas reveladora do desconcerto que assola a pátria natal do poeta. Ora, o tópico dodesconcerto (ou do mundo às avessas, com o qual se aparenta e se confunde), lembra Carlos Felipe Moisés, é em tudo contrário ao concerto, ao equilíbrio e à perfeição que caracterizam a máquina do mundo vista pelo Gama e os seus. Mais evidente na poesia lírica camoniana, nem por isso o desconcerto deixa de estar presente, de maneira sub-reptícia, n'Os Lusíadas, uma vez que é justamente a partir do Maneirismo que esse tópico ganha relevo. O livro de Moisés, $O$ desconcerto do mundo do Renascimento ao Surrealismo (2001), objetiva rastrear a maneira como esse desconcerto, então subjacente à visão clássica de mundo, maculando-a e rasurando-a, vai aflorar plenamente no século XX com a grande revolução surrealista. 
Moisés conclui que o concerto, para Camões - como para grande parte dos poetas modernos -, está apenas na máquina do poema, nessa consciência de linguagem que vinca o poeta português. O concerto, assim, "provém simplesmente da confiança que Camões deposita na própria poesia, na linguagem, na capacidade de expressão, enquanto tal. É esse o nível em que a aspiração à ordem e à harmonia se realiza" (MOISÉS 2001: 56).

O estudo das migrações de um topos como o da máquina do mundo - uma vez que as migrações, objeto da Literatura Comparada, são sempre plasmadas em temporalidades e espaços descontínuos -, revela, mais uma vez, que a máquina do poema continua a se alimentar de poesia, agora através da prática intertextual. Seja essa relação intertextual marcada pelageneralidade e pela codificação (no mundo clássico), seja exacerbando a particularidade e afragmentação (no mundo moderno), o certo é que essa prática é condição sine qua non da melhor literatura, pois ressalta, a um só tempo, o poeta enquanto leitor e enquanto autor de uma obra nova. Esta, ainda que evidentemente marcada pela peculiaridade de seu tempo e espaço, também se abre para o difícil diálogo com o passado. Isso revela não apenas a relação conflituosa do poeta com os precursores, mas também o modo como dado momento histórico-cultural recebeu a vasta herança desses precursores, problematizando-a sob variados ângulos. Moderna e contemporaneamente, a prática radical da intertextualidade crítica pode ser compreendida como a exploração (ainda que fragmentada e fragmentária, calcada e decalcada do palimpsesto da cultura) das "ruínas do passado" com as quais amparar as "ruínas do presente" (JUNQUEIRA 1987: 95).

\section{$\underline{\text { Três }}$}

De um lado, a máquina do poema: consciência estética de que o poema é um objeto construído de linguagem e que tem seus mecanismos específicos de funcionamento, os quais, conjugados pelo talento e pela consciência do poeta, devem revelar por si mesmos a ordem, a harmonia, a coesão e o equilíbrio internos do poema. $\mathrm{O}$ conceito de máquina do poema é aspecto relevante de uma teoria, de uma poética e de uma prática lírica na modernidade e na contemporaneidade, e não pode apresentar as fissuras que a máquina do mundo sempre revela em si. Essa consciência estética - ou esse autotelismo estético - é a contrapartida do individualismo extremo do homem moderno, divorciado de seu meio e há muito afastado das experiências comuns do mito, do rito, do relato, da poesia. Por seu turno, como ressalta João Cabral de Melo Neto, o poeta também está divorciado de seu leitor, pois a poesia moderna, ao perder suas funções tradicionais e sua aura, voltou-se para si mesma e para os cacos da tradição e dos valores esfacelados, em busca de uma poética que exprimisse, por sua vez, as arruinadas concepções de Deus, mundo e vida. Mas a máquina do poema sinaliza também para o humano (mesmo sem Deus), sua capacidade simbólica e sua necessidade criativa, que se abrem sempre em novas possibilidades de fazer um mundo melhor que aquele configurado pela velha máquina do mundo, sempre em desconcerto. Refratando-se todos os prismas aqui veiculados, conclui-se que a máquina do poema é também uma concepção de mundo, uma cosmovisão, uma forma específica (subjetiva e objetiva) de conhecimento: seja da própria matéria poética; seja das relações da poesia (e da 
literatura em geral) com outros sistemas culturais e artísticos; seja das experiências de mundo e de vida plasmadas pelo eu-lírico.

De outro lado, a máquina do mundo: mera representação, cosmovisão ou concepção de mundo, mas poderosamente vincada pela realidade histórica e social de cada poeta que utilizou o tema. Em Dante Alighieri e Camões, por exemplo, é representação alegórica de um mundo poeticamente idealizado e ideologicamente mantenedor de valores como a Igreja, a Monarquia, o expansionismo, o absolutismo e outras certezas absolutas (ainda que sempre abaladas pela racionalidade em crise). Modernamente, recusa de toda maravilha e de qualquer solução mágica e mítica (como em Drummond), mais o vinco de ceticismo, amargor, desesperança e o cansaço de sempre ter de palmilhar as pedregosas estradas de Minas e do mundo às avessas. E é justamente esse tópico, disfarçado nas frinchas da concepção clássica, que vai, gradativamente, maculando tal concepção e expondo as fissuras da máquina do mundo universal. Esta, enfim - e coerentemente com o mundo arruinado em que vivemos - termina sobrepujada pelo tópico do mundo às avessasou do desconcerto do mundo: caro a Camões, esse tópico pode ser rastreado também em Drummond ("A flor e a náusea", entre outros), e é bastante familiar ao leitor contemporâneo. Mas, hoje em dia, não mais se representa a máquina do mundo? Como seria, hoje, uma representação dessa máquina? Veja-se o último delírio "cosmovisionário" (a expressão é de Leda Tenório da Motta) de Haroldo de Campos, A máquina do mundo repensada (2000): poema tripartite, de estofo épico (um épico da pós-modernidade esfacelada ou "pós-utópica", dir-se-ia), dialoga ao mesmo tempo com Dante, Camões e Drummond, está solidamente amparado pelas últimas conquistas científicas (astrofísicas) e é exemplar da consciência crítico-criativa do poeta e do aproveitamento que este faz das sobras da tradição poética. No poema de Haroldo, a máquina do mundo não deixa de ser pretexto para a máquina do poema.

Um outro exemplo, bastante complexo a meu ver, é o conjunto de sete novelas de João Guimarães Rosa, Corpo de baile (1956): além da mitopoesia, está presente na obra a cosmopoesia, uma vez que o autor mineiro, a partir do sistema planetário antigo (o mesmo explorado por Dante e Camões), configura, no sertão mineiro, através de um périplo elíptico - uma ciranda cósmica, um corpo de baile astral - um mundo bastante particular cuja construção revela na argamassa vários elementos da tradição clássica e medieval, quer em termos estéticos, quer em termos de pensamento filosófico, mítico, místico e metafísico. Ressalve-se, contudo, que esta interpretação genérica e generalizante de Corpo de baile deve sempre resguardar - e salientar - a máquina poemática que é cada novela do conjunto.

\section{OBRAS CITADAS}

\section{Geral}

BARBOSA, João Alexandre. 2002. Alguma crítica. São Paulo: Ateliê.

CAMPOS, Haroldo de. 2002. "De uma cosmopoesia: sobre A máquina do mundo repensada."Depoimentos de oficina. São Paulo: Unimarco. p. 59-70.

JUNQUEIRA, Ivan. Intertextualismo e poesia contemporânea. $O$ encantador de serpentes. Rio de Janeiro: Alhambra, 1987. p. 85-95. 
MELO NETO, João. 1998. Cabral. Prosa. Rio de Janeiro: Nova Fronteira. MOISÉS, Carlos Felipe. 2001. "A máquina do mundo." O desconcerto do mundo do Renascimento ao Surrealismo. São Paulo: Escrituras. p. 23-57.

MOTTA, Leda Tenório da. 2002. "Desastre de astros: Sobre o último Haroldo de Campos cosmovisionário." Sobre a crítica literária brasileira no último meio século. Rio de Janeiro: Imago. p. 163-187.

NUNES, Benedito. 1976. "A máquina do poema." O dorso do tigre. 2. ed. São Paulo: Perspectiva. p. 265-275.

SANT'ANNA, Affonso Romano de. 1972. "O enigma se esclarece." Drummond o gauche no tempo. Rio de Janeiro: Lia.

2. Obras literárias

ALIGHIERI, Dante. 2002. A divina comédia. Tradução e notas de Ítalo Eugenio Mauro. 3 vols. São Paulo: Editora 34.

ANDRADE, Carlos Drummond de. 1980. Antologia poética. 14. ed. Rio de Janeiro: J. Olympio.

—. 2002. Poesia completa. Rio de Janeiro: Nova Aguilar, 2002.

CAMÕES, Luís de. 1979. Os Lusíadas. São Paulo: Abril.

—. 1991. Lírica. Seleção, prefácio e notas de Massaud Moisés. São Paulo: Cultrix,.

CAMPOS, Haroldo de. 2000. A máquina do mundo repensada. São Paulo: Ateliê.

MELO NETO, João Cabral. 1997a. Serial e antes. Rio de Janeiro: Nova Fronteira.

—. 1997b. A educação pela pedra e depois. Rio de Janeiro: Nova Fronteira.

ROSA, João Guimarães. 1996. Manuelzão e Miguilim (Corpo de baile). 9. ed. Rio de Janeiro: Nova Fronteira.

—. 1978. No Urubuquaquá, no Pinhém (Corpo de baile). 6. ed. Rio de Janeiro: J. Olympio.

—. 1979. Noites do sertão (Corpo de baile). 6. ed. Rio de Janeiro: J. Olympio. 